http://www.jfas.info

\title{
ENHANCED INFLAMMATION IN SUBGROUPS OF METABOLIC SYNDROME IRRESPECTIVE OF GLYCAEMIC STATUS
}

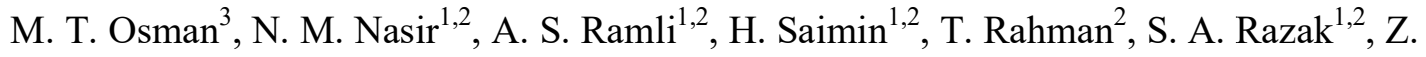 \\ Ismail $^{1,2}$ and H. M. Nawawi ${ }^{1,2, *}$ \\ ${ }^{1}$ Institute of Pathology, Laboratory and Forensic Medicine (I-PPerForM), UniversitiTeknologi \\ MARA, Selangor, Malaysia \\ ${ }^{2}$ Faculty of Medicine, UniversitiTeknologi MARA, Selangor, Malaysia \\ ${ }^{3}$ Faculty of Medicine and Defence Health, National Defence University of Malaysia (UPNM), \\ Kuala Lumpur, Malaysia
}

Published online: 10 November 2017

\begin{abstract}
The objectives of this study were toinvestigate the inflammation and endothelial activation biomarkers in subjects with metabolic syndrome (MS)subgroups irrespective of glycaemic status. Subjects $(n=319)$ were categorized into MS subgroups [diabetes mellitus (MSDM), impaired fastig glucose (MSIFG) and normoglycemia (MSNG)] and normal controls (NC). Inflammatory biomarkers (high-sensitivity C-reactive protein and interleukin-6) and endothelial activation (soluble intercellular adhesion molecule-1, vascular cell adhesion molecule-1 and E-selectin) were measured and compared between the groups.MS subjects had significant increase in all biomarkers compared to NC subjects. Glycaemic status in MS subgroups did not show any association with the quartiles of all biomarkers, except for interleukin-6. This may partially explain their increased coronary risk.
\end{abstract}

Keywords: metabolic syndrome; glycaemic status; inflammation; endothelial activation.

\footnotetext{
Author Correspondence, e-mail: hapizah.nawawi@gmail.com

doi: http://dx.doi.org/10.4314/jfas.v9i6s.26
} 


\section{INTRODUCTION}

The metabolic syndrome (MS) is a major and escalating clinical challenge and public-health worldwide in the wake of urbanization, surplus energy intake, increasing obesity and sedentary life habits [1]. MS confers a 5-fold increase in the risk of type 2 diabetes mellitus (T2DM) and 2-fold the risk of developing coronary heart disease (CHD) over the next years [1-2].

MS is defined by a constellation of an interconnected physiological, biochemical, clinical, and metabolic factors that associated with increases the risk of atherosclerotic coronary heart disease (ASCHD), T2DM and all-cause mortality [3-4]. These abnormal test results and the collection of unhealthy body measurements include proinflammatory state, prothrombotic state, hypertension, atherogenicdyslipidaemia and glucose intolerance[1].

MS is a clinical manifestation of insulin resistance [5]. Its frequency in type 1 diabetes (T1DM) is around 20\% [1-4]. MS is an independent risk factor for vascular complications and for progression of the disease [6-7]. The mechanisms of MS in T1DM remain poorly defined but some are likely to be similar to those proposed in type 2 diabetes (T2DM) i.e. accentuated ectopic fat accretion, enhanced lipolysis and inhibited insulin-stimulated glucose uptake [8-10].

The prevalence of the metabolic syndrome has been shown to be significantly higher in each age-group of patients with type 2 diabetes in comparison to the general population [5].

Coronary heart disease (CHD) is a major cause of morbidity and the leading cause of mortality among people with diabetes mellitus [11]. People with diabetes mellitus have a higher prevalence of other coronary risk factors, including hyperlipidaemia and hypertension [12-13]. Moreover, chronic hyperglycaemia is a risk factor for atherosclerosis in diabetes mellitus [14]. However, neither traditional CHD risk factors nor hyperglycaemia fully explains the risk for CHD. An additional factor that may play a role in the increased risk of CHD among diabetics is an increase in the overall level of systemic inflammation[11].

As well-known the characteristic feature of the atherosclerotic process in its course is a significant intensity [15]. Both obesity which is a major risk factor for the insulin resistance development and T2DM and the chronic hyperglycaemia itself play an important role in its pathogenesis. Hyperglycaemia contributes to glycosylation of proteins and lipids, increases 
the production of reactive oxygen species, stimulates the synthesis and secretion of pro-inflammatory cytokines and acute phase proteins in various tissues, promoting thus inflammation processes in the vascular wall [15-18].

Although there have been some reports on coronary risk biomarkers in metabolic syndrome [19-21], there is scarce data on the influence of different glycaemic status in MS subjects (diabetes mellitus, impaired fasting glucose or normoglycemia) on inflammation and endothelial activation biomarkers. Furthermore, usage of medications that may affect the concentration of the biomarkers could become confounding factors if not excluded. Therefore, this present study was undertaken with the objectives to: 1) examine the inflammation and endothelial activation biomarkers in drug-naive MS subjects compared to lean normal controls; 2) investigate the influence of different glycaemic status (diabetes mellitus, impaired fasting glucose or normoglycemia) in MS subjects on biomarkers of inflammation and endothelial activation; and 3) ascertain the independent determinants of these biomarkers.

\section{EXPERIMENTAL}

\subsection{Study Design and Subject Selection}

This cross-sectional study involved a total of 319 subjects aged 30-65 years old, recruited from UniversitiTeknologi MARA (UiTM) Malaysia Specialist Clinics and community health screenings. Sample size was calculated using OpenEpi software with power of study set at $80 \%$ and $\alpha$-level at 0.05 , yielding the minimum number of 60 subjects for each group. Institutional Ethics Committee approval was obtained prior to commencement of the study from the Institutional Board ofUniversitiTeknologi MARA (UiTM) [ref no.: 600-RMI (5/1/6)] and all subjects gave written informed consent. For each subject, a set of questionnaire was completed and detailed history taking including smoking habits, alcohol intake and family history or premature coronary heart disease (history of ischemic heart disease, myocardial infarction or sudden death at the age of $<55$ years in males and $<65$ years in females in first-degree relatives) were documented.

Recruited subjects were categorized into MS ( $n=223)$ and normal lean control $(\mathrm{NC}, \mathrm{n}=96)$ groups, and matched for age, gender and smoking status. The MS subjects were then subdivided into 3 groups according to glycaemic status: 1) MS with diabetes mellitus (MSDM, 
$\mathrm{n}=62$ ); 2) MS with impaired fasting glucose (MSIFG, $\mathrm{n}=91$ ); and 3) MS with normoglycemia (MSNG, $\mathrm{n}=70$ ). The MS subgroups were matched for age, gender, smoking status, obesity indices, blood pressure and lipid profile.

\subsection{Inclusion and Exclusion Criteria}

MS was defined according to the 2006 International Diabetes Federation (IDF) definition [38].Individuals were considered to have MS if they were centrally obese (elevated waist circumference: $\geq 90 \mathrm{~cm}$ in men, $\geq 80 \mathrm{~cm}$ in women) with at least 2 out of 4 of the following criteria: elevated triglycerides $(\mathrm{TG}) \geq 1.7 \mathrm{mmol} / \mathrm{L}$; reduced high density lipoprotein cholesterol $($ HDL-c) $<1.0 \mathrm{mmol} / \mathrm{L}$ in $\mathrm{men},<1.3 \mathrm{mmol} / \mathrm{L}$ in women; elevated blood pressure [systolic blood pressure $(\mathrm{SBP}) \geq 130 \mathrm{mmHg}$ and/or diastolic blood pressure $(\mathrm{DBP}) \geq 85$ $\mathrm{mmHg}$ ] or elevated fasting glucose $\geq 5.6 \mathrm{mmol} / \mathrm{L}]$.

Diabetes mellitus (DM), impaired fasting glucose (IFG) and normoglycemia (NG) were defined as those with fasting plasma glucose $(\mathrm{FPG}) \geq 7.0 \mathrm{mmol} / \mathrm{L}, 5.6-6.9 \mathrm{mmol} / \mathrm{L}$ and $<5.6$ $\mathrm{mmol} / \mathrm{L}$ respectively [28].

Subjects with waist circumference of $\geq 90 \mathrm{~cm}$ for men and $\geq 80 \mathrm{~cm}$ for women with 0 or 1 other component of MS (elevated BP, raised TG or low HDL-c) were grouped as COBXMS. Normal controls were lean (WC $<90 \mathrm{~cm}$ in men, $<80 \mathrm{~cm}$ in women), normotensive (SBP $<$ $130 \mathrm{mmHg}$ and $\mathrm{DBP}<85 \mathrm{mmHg})$, normoglycemic $(\mathrm{FPG}<5.6 \mathrm{mmol} / \mathrm{L})$ subjects with $\mathrm{TG}<$ $1.7 \mathrm{mmol} / \mathrm{L}$ and HDL-c $\geq 1.0 \mathrm{mmol} / \mathrm{L}$ in $\mathrm{men}$ and $\geq 1.3 \mathrm{mmol} / \mathrm{L}$ in women.

Exclusion criteria for this study were those on oral hypoglycaemic agents or insulin, lipid lowering or anti-hypertensive medications, on long term antioxidant or anti-inflammatory therapy and subjects with chronic inflammatory disorders, malignancy or severe diseases that shorten life expectancy.

\subsection{Anthropometric and Blood Pressure Measurement}

Anthropometric measurements including height, weight, body mass index (BMI) and waist circumference (WC) were obtained using standardized techniques. Body weight and height (to the nearest $0.1 \mathrm{~kg}$ and $0.01 \mathrm{~m}$ respectively) were measured in light clothing without shoes using a pre-calibrated Seca digital scale and height rod. BMI was calculated as weight $(\mathrm{kg})$ divided by squared height $\left(\mathrm{m}^{2}\right)$. Waist circumference was measured (to the nearest $0.5 \mathrm{~cm}$ ) using a measuring tape midway between the inferior margin of the last palpable rib and the 
top of the iliac crest. Blood pressure was taken using an automated BP monitor (Omron, USA) on the right arm with the subject in a seated position and the right arm supported at heart level, after at least 5 minutes rest. BP was measured three times in each subject and average of the last two readings was taken as the subject's BP.

\subsection{Biochemical Analysis}

Fasting venous blood samples were collected and centrifuged at 3,500 rpm for 10 minutes within 2 hours after collection. Serum and plasma were aliquoted and stored at $-20^{\circ} \mathrm{C}$ until analysis. Samples were assayed for routine biochemistry tests such as fasting lipid profile and fasting plasma glucose using standardized assays on an automated analyzer (Cobas Integra 400 plus, Roche Systems, Germany). The intra- and inter-assay coefficient of variation (CV) for the biochemical assays ranged between $0.5 \%$ and $1.9 \%$.

\subsection{Markers of Inflammation and Endothelial Activation}

Inflammatory markers measured were high sensitivity C-reactive protein (hsCRP) and interleukin-6 (IL-6) while the endothelial activation markers include soluble intercellular adhesion molecule 1 (sICAM-1), soluble vascular cell adhesion molecule 1 (sVCAM-1) and soluble E-selectin (E-selectin).

hsCRP measurement was based on a particle enhanced immunoturbidimetric method on an automated analyzer (Cobas Integra 400 plus, Roche Systems, Germany), while IL-6, sICAM-1, sVCAM-1 and E-selectin were measured using commercial enzyme-linked immunosorbent assay (ELISA) kits (eBioscience, Austria). The intra- and inter-assay CV for hs-CRP were $0.8 \%$ and $2.9 \%$ respectively, while the intra- and inter-assay CV of the immunosorbent assays ranged between $5.7 \%$ and $16.9 \%$.

\subsection{Statistical Analysis}

Statistical analyses were carried out using Statistical Program for Social Science Software (SPSS) version 16.0 (SPSS inc. Chicago II, USA 2008). Normality testing was determined by Kolmogorov Smirnov test. Data were expressed as mean \pm standard deviation (SD) or proportions (\%). Data for all biomarkers were $\log _{10}$ transformed to improve the normality and used in subsequent analyses. Comparison of continuous variables between study groups was performed using one-way Analysis of Variance (ANOVA), followed by post-hoc Scheffe or Dunnett's T3 test depending on the result of Levene statistic. Correlation between two 
continuous data was analysed by Pearson's correlation coefficient test. Multiple linear regression analysis was used to further investigate the influence of conventional cardiovascular risk factors on inflammation and endothelial activation biomarkers. Forward, backward and stepwise multiple linear regressions were performed and thebest fit modelwas selected. Level of significance was set at $\mathrm{p}<0.05$.

\section{RESULTSAND DISCUSSION}

The characteristics of the 319 study subjects are presented in Table 1. All subjects of two groups (MS and NC) were matched for age, gender and smoking status. The mean age $( \pm \mathrm{SD})$ of the subjects were $47.6( \pm 8.4)$ years old; comprising of $204(63.9 \%)$ females and 115 $(36.1 \%)$ males.

Subjects with MS had lower HDL-c and significantly higher BMI, WC, SBP and DBP, TG and FPG $(\mathrm{p}<0.001)$ with slightly higher total cholesterol $(\mathrm{TC}, \mathrm{p}<0.05)$ concentrations compared to NC. With regard to biomarkers of inflammation and endothelial activation, MS subjects had significantly elevated concentrations of all biomarkers compared to normal controls (Table 1). 
Table 1. Baseline characteristics of subjects and concentration of inflammation andendothelial biomarkers in MS and NC groups

\begin{tabular}{ccc}
\hline Parameter & MS(n=223) & NC(n=96) \\
\hline${ }^{\mathrm{a}}$ Age (years) & $48.7 \pm 8.4$ & $46.2 \pm 7.8$ \\
${ }^{\mathrm{b}}$ Gender (Male/Female) & $82 / 141(36.8 / 63.2)$ & $33 / 63(34.4 / 65.6)$ \\
${ }^{\mathrm{b}}$ Current smoker & 12.1 & 14.3 \\
${ }^{\mathrm{a}} \mathrm{BMI}\left(\mathrm{kg} / \mathrm{m}^{2}\right)$ & $29.5 \pm 4.1$ & $21.9 \pm 2.5$ \\
${ }^{\mathrm{a}} \mathrm{WC}(\mathrm{cm})$ & $94.4 \pm 8.8$ & $73.8 \pm 7.7$ \\
${ }^{\mathrm{a}}$ Systolic BP (mmHg) & $138.7 \pm 22.4$ & $112.8 \pm 10.0$ \\
${ }^{\mathrm{a}}$ Diastolic BP (mmHg) & $84.5 \pm 12.8$ & $69.9 \pm 8.4$ \\
${ }^{\mathrm{a}} \mathrm{TC}(\mathrm{mmol} / \mathrm{L})$ & $6.0 \pm 1.1$ & $5.6 \pm 1.0$ \\
${ }^{\mathrm{a}}$ Triglyceride (mmol/L) & $2.3 \pm 1.2$ & $1.0 \pm 0.3$ \\
${ }^{\mathrm{a}} \mathrm{HDL}-\mathrm{c}(\mathrm{mmol} / \mathrm{L})$ & $1.1 \pm 0.3$ & $1.6 \pm 0.4$ \\
${ }^{\mathrm{a}} \mathrm{LDL}-\mathrm{c}(\mathrm{mmol} / \mathrm{L})$ & $3.8 \pm 1.0$ & $3.5 \pm 1.0$ \\
${ }^{\mathrm{a}}$ Glucose (mmol/L) & $7.4 \pm 3.3$ & $4.9 \pm 0.5$ \\
Biomarkers of inflammation and endothelial activation \\
${ }^{\mathrm{a}}$ Log sVCAM-1 (ng/ml) & $3.09 \pm 0.3$ & $0.27 \pm 0.2$ \\
${ }^{\mathrm{a}}$ Log Eoghs-CRP (mg/L) & $0.54 \pm 0.3$ & $0.55 \pm 0.2$ \\
${ }^{\mathrm{a}}$ Log IL-6 (pg/ml) & $0.65 \pm 0.2$ & $2.62 \pm 0.2$ \\
\hline
\end{tabular}

Data are expressed as ${ }^{\mathrm{a}}$ mean $\pm \mathrm{SD}$ or ${ }^{\mathrm{b}}$ percentage

Out of the 223 MS subjects, 62 (27.8\%) had diabetes mellitus, 91 (40.8\%) had IFG and 70 (31.4\%) were normoglycemic. The MS subgroups (MSDM, MSIFG and MSNG) were matched for age, gender, smoking status, BMI, WC, blood pressure and lipid profile. The concentrations of inflammation and endothelial activation biomarkers were not significantly dissimilar among the MS subgroups with different glycaemic status (Table 2). 
Table 2. Baseline characteristics of subjects and concentration of inflammation and endothelial biomarkers according to glycaemic status in metabolic syndrome subjects

\begin{tabular}{|c|c|c|c|c|c|c|}
\hline Parameter & $\begin{array}{l}\text { MSDM } \\
(n=62)\end{array}$ & $\begin{array}{l}\text { MSIFG } \\
(n=91)\end{array}$ & $\begin{array}{l}\text { MSNG } \\
(n=70)\end{array}$ & $\begin{array}{c}\text { p-Value } \\
\text { (MSDM } \\
\text { vs. } \\
\text { MSNG) }\end{array}$ & $\begin{array}{l}\text { p-Value } \\
\text { (MSIFG } \\
\text { vs. } \\
\text { MSNG) }\end{array}$ & $\begin{array}{c}\text { p-Value } \\
\text { (MSDM } \\
\text { vs. } \\
\text { MSIFG) }\end{array}$ \\
\hline${ }^{\mathrm{a}}$ Age (years) & $49.2 \pm 6.7$ & $49.2 \pm 8.6$ & $47.7 \pm 9.4$ & & NS & \\
\hline${ }^{\mathrm{b}}$ Gender (Male / & $23 / 39$ & $40 / 51$ & $19 / 51$ & & NS & \\
\hline Female) & $(37.1 / 62.9)$ & $(44.0 / 56.0)$ & $(27.1 / 72.9)$ & & & \\
\hline${ }^{\mathrm{b}}$ Current smoker & 11.3 & 13.2 & 11.4 & & NS & \\
\hline${ }^{\mathrm{a}} \mathrm{BMI}\left(\mathrm{kg} / \mathrm{m}^{2}\right)$ & $29.2 \pm 3.8$ & $29.3 \pm 3.9$ & $30.1 \pm 4.6$ & & NS & \\
\hline${ }^{\mathrm{a}} \mathrm{WC}(\mathrm{cm})$ & $93.5 \pm 9.4$ & $95.0 \pm 8.4$ & $94.4 \pm 8.8$ & & NS & \\
\hline${ }^{\mathrm{a}}$ Systolic BP & $139.7 \pm$ & $136.8 \pm$ & $140.1 \pm$ & & NS & \\
\hline$(\mathrm{mmHg})$ & 23.1 & 22.7 & 21.6 & & & \\
\hline${ }^{\mathrm{a}}$ Diastolic BP & $85.9 \pm 13.0$ & $82.2 \pm$ & $86.3 \pm 12.7$ & & NS & \\
\hline$(\mathrm{mmHg})$ & & 12.7 & & & & \\
\hline${ }^{\mathrm{a}} \mathrm{TC}(\mathrm{mmol} / \mathrm{L})$ & $6.1 \pm 1.0$ & $6.0 \pm 1.1$ & $5.8 \pm 1.2$ & & NS & \\
\hline $\begin{array}{l}{ }^{\mathrm{a}} \text { Triglyceride } \\
(\mathrm{mmol} / \mathrm{L})\end{array}$ & $2.4 \pm 1.2$ & $2.2 \pm 1.1$ & $2.3 \pm 1.1$ & & NS & \\
\hline${ }^{\mathrm{a}} \mathrm{HDL}-\mathrm{c}(\mathrm{mmol} / \mathrm{L})$ & $1.2 \pm 0.3$ & $1.1 \pm 0.3$ & $1.1 \pm 0.2$ & & NS & \\
\hline${ }^{\mathrm{a}} \mathrm{LDL}-\mathrm{c}(\mathrm{mmol} / \mathrm{L})$ & $3.9 \pm 1.0$ & $3.9 \pm 1.0$ & $3.6 \pm 1.0$ & & NS & \\
\hline${ }^{\mathrm{a}}$ Glucose $(\mathrm{mmol} / \mathrm{L})$ & $11.4 \pm 3.7$ & $6.5 \pm 1.2$ & $5.0 \pm 0.5$ & $* * *$ & $* * *$ & $* * *$ \\
\hline \multicolumn{7}{|c|}{ Biomarkers of inflammation and endothelial activation } \\
\hline $\begin{array}{c}{ }^{\mathrm{a}} \text { Log hs-CRP } \\
(\mathrm{mg} / \mathrm{L})\end{array}$ & $0.58 \pm 0.3$ & $0.52 \pm 0.3$ & $0.54 \pm 0.3$ & & NS & \\
\hline${ }^{\mathrm{a}} \log \operatorname{IL}-6(\mathrm{pg} / \mathrm{ml})$ & $0.65 \pm 0.2$ & $0.67 \pm 0.2$ & $0.63 \pm 0.3$ & & NS & \\
\hline $\begin{array}{c}{ }^{\mathrm{a}} \log \text { sICAM-1 } \\
(\mathrm{ng} / \mathrm{ml})\end{array}$ & $2.72 \pm 0.2$ & $2.76 \pm 0.2$ & $2.76 \pm 0.2$ & & NS & \\
\hline${ }^{\mathrm{a}} \log$ s VCAM-1 & $3.17 \pm 0.3$ & $3.06 \pm 0.3$ & $3.05 \pm 0.3$ & & NS & \\
\hline
\end{tabular}


$(\mathrm{ng} / \mathrm{ml})$

$\begin{array}{lllll}{ }^{\mathrm{a}} \log \text { E-Selectin } & 1.71 \pm 0.2 & 1.72 \pm 0.3 & 1.68 \pm 0.3 & \text { NS }\end{array}$

$(\mathrm{ng} / \mathrm{ml})$

Data are expressed as ${ }^{a}$ mean $\pm \mathrm{SD}$, or ${ }^{b}$ percentage. ${ }^{*} \mathrm{p}<0.05,{ }^{* *} \mathrm{p}<0.01,{ }^{* * *} \mathrm{p}<0.001$, NS: not significant

MSDM: metabolic syndrome with diabetes mellitus; MSIFG: metabolic syndrome with impaired fasting glucose; MSNG: metabolic syndrome with normoglycemia; BMI: body mass index; WC: waist circumference; BP: blood pressure; TC: total cholesterol; HDL-c: high density lipoprotein cholesterol; LDL-c: low density lipoprotein cholesterol; hs-CRP: high sensitivity C-reactive protein; IL-6: interleukin-6; sICAM-1: soluble intercellular adhesion molecule-1; sVCAM-1: soluble vascular cell adhesion molecule-1.

Table 3 shows that in the MS subgroups (MSDM, MSIFG and MSNG), glycaemic status did not show any association with the quartiles of all biomarkers except for IL-6 which showed only marginal association ( $\mathrm{p}=0.048$, Table 4$)$.

Based on Pearson's correlation analysis performed on all subjects, BMI and WC were shown to have small but significant positive correlations with hsCRP, sICAM-1, E-selectin $(p<0.001)$ and IL-6 $(\mathrm{p}<0.01)$. Meanwhile, positive correlations were observed between TG and E-selectin and between blood pressure and sVCAM-1 and E-selectin $(p<0.001)$. HDL-c was shown to be inversely correlated with the endothelial activation biomarkers. Glucose showed positive correlations with hsCRP, sVCAM-1 and E-selectin. However, glucose concentration did not show correlation with any biomarker when Pearson's correlation analysis was performed in MS subjects only (Table 4). 
Table 3. Association between glycaemic status in MS subjects with quartiles of biomarkers of inflammation and endothelial activation

\begin{tabular}{|c|c|c|c|c|}
\hline Biomarker & $\begin{array}{l}\text { MSDM } \\
\text { n (\%) }\end{array}$ & $\begin{array}{c}\text { MSIFG } \\
\text { n (\%) }\end{array}$ & $\begin{array}{l}\text { MSNG } \\
\text { n (\%) }\end{array}$ & p-Value \\
\hline \multicolumn{5}{|c|}{ Log hs-CRP (mg/L) } \\
\hline Q1: < 0.30 & $7(4.1)$ & $22(12.9)$ & $13(7.6)$ & \multirow{4}{*}{ NS } \\
\hline Q2: $0.30-0.53$ & $15(8.8)$ & $15(8.8)$ & $13(7.6)$ & \\
\hline Q3: 0.54-0.78 & $13(7.6)$ & $14(8.2)$ & $12(7.0)$ & \\
\hline $\mathrm{Q} 4: \geq 0.79$ & $16(9.4)$ & $18(10.5)$ & $13(7.6)$ & \\
\hline \multicolumn{5}{|c|}{ Log IL-6 (pg/ml) } \\
\hline Q1: < 0.53 & $15(7.3)$ & $12(5.8)$ & $24(11.7)$ & \multirow{4}{*}{0.048} \\
\hline Q2: 0.53-0.62 & $13(6.3)$ & $23(11.2)$ & $11(5.3)$ & \\
\hline Q3: 0.63-0.76 & $16(7.8)$ & $28(13.6)$ & $12(5.8)$ & \\
\hline $\mathrm{Q} 4: \geq 0.77$ & $16(7.8)$ & $20(9.7)$ & $16(7.8)$ & \\
\hline \multicolumn{5}{|c|}{ Log sICAM-1 (ng/ml) } \\
\hline Q1: <2.63 & $15(7.0)$ & $22(10.3)$ & $14(6.6)$ & \multirow{4}{*}{ NS } \\
\hline Q2: 2.63-2.73 & $18(8.5)$ & $19(8.9)$ & $13(6.1)$ & \\
\hline Q3: 2.74-2.86 & $14(6.6)$ & $19(8.9)$ & $24(11.3)$ & \\
\hline Q4: $\geq 2.87$ & $12(5.6)$ & $26(12.2)$ & $17(8.0)$ & \\
\hline \multicolumn{5}{|c|}{ Log sVCAM-1 (ng/ml) } \\
\hline Q1: $<2.88$ & $9(4.1)$ & $21(9.6)$ & $22(10.1)$ & \multirow{4}{*}{ NS } \\
\hline Q2: 2.88-3.05 & $15(6.9)$ & $26(11.9)$ & $13(6.0)$ & \\
\hline Q3: 3.06-3.33 & $13(6.0)$ & $22(10.1)$ & $20(9.2)$ & \\
\hline Q4: $\geq 3.34$ & $24(11.0)$ & $19(8.7)$ & $14(6.4)$ & \\
\hline \multicolumn{5}{|c|}{ Log E-Selectin (ng/ml) } \\
\hline Q1: < 1.49 & $10(4.5)$ & $27(12.3)$ & $17(7.7)$ & \multirow{4}{*}{ NS } \\
\hline Q2: 1.49-1.68 & $21(9.5)$ & $17(7.7)$ & $17(7.7)$ & \\
\hline Q3: $1.69-1.90$ & $20(9.1)$ & $17(7.7)$ & $17(7.7)$ & \\
\hline $\mathrm{Q} 4: \geq 1.91$ & $11(5.0)$ & $28(12.7)$ & $18(8.2)$ & \\
\hline
\end{tabular}

MSDM: metabolic syndrome with diabetes mellitus; MSIFG: metabolic syndrome with 
impaired fasting glucose; MSNG: metabolic syndrome with normoglycemia; hs-CRP: high sensitivity C-reactive protein; IL-6: interleukin-6; sICAM-1: soluble intercellular adhesion molecule-1; sVCAM-1: soluble vascular cell adhesion molecule-1; NS: not significant.

Table 4. Correlation between biomarkers of inflammation and endothelial activation with components of metabolic syndrome

\begin{tabular}{|c|c|c|c|c|c|}
\hline Parameters & $\begin{array}{c}\text { Log hsCRP } \\
(\mathrm{mg} / \mathrm{L})\end{array}$ & $\begin{array}{c}\text { Log IL-6 } \\
(\mathrm{pg} / \mathrm{ml})\end{array}$ & $\begin{array}{c}\text { Log } \\
\text { sICAM-1 } \\
(\mathrm{ng} / \mathrm{ml})\end{array}$ & $\begin{array}{c}\text { Log } \\
\text { sVCAM-1 } \\
(\mathrm{ng} / \mathrm{ml})\end{array}$ & $\begin{array}{c}\text { Log } \\
\text { E-Selectin } \\
(\mathrm{ng} / \mathrm{ml})\end{array}$ \\
\hline $\begin{array}{c}{ }^{\mathrm{a}} \mathrm{BMI} \\
\left(\mathrm{kg} / \mathrm{m}^{2}\right)\end{array}$ & $0.284 * * *$ & $0.148 * *$ & $0.229 * * *$ & 0.086 & $0.273 * * *$ \\
\hline $\begin{array}{l}{ }^{\mathrm{a}} \mathrm{WC} \\
(\mathrm{cm})\end{array}$ & $0.239 * * *$ & $0.156^{* *}$ & $0.259 * * *$ & 0.090 & $0.332 * * *$ \\
\hline $\begin{array}{l}{ }^{\mathrm{a}} \text { HDL-c } \\
(\mathrm{mmol} / \mathrm{L})\end{array}$ & 0.006 & 0.030 & $-0.098^{*}$ & $-0.142 * *$ & $-0.274 * * *$ \\
\hline $\begin{array}{c}{ }^{\mathrm{a}} \mathrm{TG} \\
(\mathrm{mmol} / \mathrm{L})\end{array}$ & 0.011 & 0.006 & 0.073 & 0.087 & $0.240 * * *$ \\
\hline $\begin{array}{c}{ }^{\mathrm{a}} \mathrm{SBP} \\
(\mathrm{mmHg})\end{array}$ & 0.074 & 0.045 & -0.004 & $0.200 * * *$ & $0.262 * * *$ \\
\hline $\begin{array}{c}{ }^{\mathrm{a}} \mathrm{DBP} \\
(\mathrm{mmHg})\end{array}$ & 0.061 & $0.149 * *$ & 0.066 & $0.176^{* * *}$ & $0.229 * * *$ \\
\hline $\begin{array}{l}{ }^{\mathrm{a} G l u c o s e} \\
(\mathrm{mmol} / \mathrm{L})\end{array}$ & $0.143^{* *}$ & 0.002 & 0.082 & $0.180^{* * *}$ & $0.119^{* *}$ \\
\hline $\begin{array}{l}{ }^{\mathrm{b}} \text { Glucose } \\
(\mathrm{mmol} / \mathrm{L})\end{array}$ & 0.102 & 0.005 & 0.072 & 0.111 & -0.019 \\
\hline \multicolumn{6}{|c|}{$\begin{array}{l}\text { Data are expressed as Pearson's correlation coefficient }(\mathrm{r}) \text { analyzed in all subjects or }{ }^{\mathrm{b}} \\
\text { metabolic syndrome subjects only; ***p<0.001, **p<0.01, *p<0.05, NS: not significant; } \\
\text { hs-CRP: high sensitivity C-reactive protein; IL-6: interleukin-6; sICAM-1: soluble } \\
\text { intercellular adhesion molecule-1; sVCAM-1: soluble vascular cell adhesion molecule-1; BMI: } \\
\text { body mass index; WC: waist circumference; HDL-c: high density lipoprotein cholesterol; TG: }\end{array}$} \\
\hline
\end{tabular}


triglycerides; SBP: systolic blood pressure; DBP: diastolic blood pressure.

The summary of the multiple linear regression analysis performed in all subjects is presented in Table 5. Using log hsCRP as the dependent variable, we found that BMI, log sVCAM-1, $\log$ IL-6, the female gender, glucose were the independent determinants $\left(\mathrm{R}^{2}=0.182, \mathrm{p}=0.0001\right)$; while $\log$ IL-6 was independently associated with $\log$ hsCRP, and DBP $\left(\mathrm{R}^{2}=0.241, \mathrm{p}=0.0001\right)$. Waist circumference $(B=0.004)$ and age $(B=0.006)$ were the independent determinant of $\log$ sICAM-1 $\left(\mathrm{R}^{2}=0.067, \mathrm{p}=0.0001\right)$ and $\log$ E-selectin $\left(\mathrm{R}^{2}=0.022, \mathrm{p}=0.001\right)$ respectively while $\log$ hs-CRP and glucose were the significant determinants of $\log$ sVCAM-1 $\left(\mathrm{R}^{2}=0.252\right.$, $\mathrm{p}=0.0001)$.

Table 5. Multiple linear regression analysis in all subjects using inflammation and endothelial activation biomarkers as the dependent variable

\begin{tabular}{|c|c|c|c|c|c|}
\hline $\begin{array}{c}\text { Dependent } \\
\text { Variable }\end{array}$ & $\begin{array}{c}\text { Independent } \\
\text { Variable }\end{array}$ & Coefficient & S.E. & $\begin{array}{c}\text { 95\% Confidence } \\
\text { Interval }\end{array}$ & p-Value \\
\hline \multirow{7}{*}{ Log hs-CRP } & BMI & 0.017 & 0.003 & $0.010,0.024$ & 0.0001 \\
\hline & $\log$ & & & & \\
\hline & sVCAM-1 & 0.135 & 0.052 & $0.034,0.237$ & 0.009 \\
\hline & Log IL-6 & 0.192 & 0.070 & $0.055,0.329$ & 0.006 \\
\hline & Female & 0.091 & 0.033 & $0.027,0.155$ & 0.006 \\
\hline & Glucose & 0.014 & 0.006 & $0.003,0.025$ & 0.010 \\
\hline & Indian & 0.242 & 0.102 & $0.041,0.444$ & 0.019 \\
\hline \multirow{3}{*}{ Log IL-6 } & Log hs-CRP & 0.136 & 0.042 & $0.054,0.218$ & 0.001 \\
\hline & Bumiputera & 0.480 & 0.215 & $0.058,0.902$ & 0.026 \\
\hline & DBP & 0.002 & 0.001 & $0.0001,0.004$ & 0.033 \\
\hline Log sICAM-1 & WC & 0.004 & 0.001 & $0.003,0.006$ & 0.0001 \\
\hline \multirow{2}{*}{ Log sVCAM-1 } & Log hs-CRP & 0.180 & 0.056 & $0.070,0.291$ & 0.002 \\
\hline & Glucose & 0.017 & 0.006 & $0.006,0.028$ & 0.004 \\
\hline Log E-selectin & Age & 0.006 & 0.002 & $0.002,0.009$ & 0.001 \\
\hline
\end{tabular}

hs-CRP: high sensitivity C-Reactive Protein; BMI: body mass index; sVCAM-1: soluble Vascular Cell Adhesion Molecule-1; IL-6: Interleukin-6; DBP: diastolic blood pressure; 
sICAM-1: soluble Intercellular Cell Adhesion Molecule-1; WC: waist circumference.

The present study demonstrated that subjects with MS have an enhanced inflammation and endothelial activation status compared to normal controls which was reflected by the significantly higher hsCRP, IL-6, sICAM-1, sVCAM-1 and E-selectin concentrations. It is interesting to note that more elevated concentrations of sVCAM-1 and E-selectin were observed in subjects with MS compared to NS group. The increase in biomarkers may be attributed to MS components other than WC such as TG, HDL, BP and glucose. A significantly higher proportion of MS subjects were also found in the highest quartile of each biomarker of inflammation and endothelial activation compared to NC group. All these findings reinforce the results of previous researches associating MS with biomarkers of inflammation [22-23] and endothelial activation [22,24].

Subjects of MS demonstrated an augmented inflammatory and endothelial activation state. They have higher concentrations of all biomarkers compared to normal controls. Our findings are in keeping with previous studies which have reported a significant association between elevated hsCRP[25-27] and IL-6 [25-26] and E-selectin[27]. In this present study, small but significant positive correlations were observed between BMI and WC with concentrations of hsCRP, IL-6, sICAM-1 and E-selectin. Multiple regression analysis revealed BMI as one of the significant determinants of hsCRP, while WC was the only independent determinant of sICAM-1.These findings are in agreement with previous studies which demonstrated higher concentration of prothrombogenesis and inflammatory biomarkers represented by PAI-1, IL-6 and hs-CRP in metabolic syndrome subjects [22,28-29]. Thus, these findings support the proposition that there is enhanced prothromboticand pro-inflammatory states in individual with metabolic syndrome.

Indeed several studies have suggested that inflammation is a key player in the development of CHD and a number of studies have found that several circulating molecules involved in inflammation such as sICAM-1, hsCRPpredict risk of CHD [11]. Moreover, raised circulating levels of adhesion molecules are thought to indicate a state of endothelial activation with consequent induction of immunological activity [30-31]. Levels of sICAM-115 but not sVCAM-141 predict future cardiovascular events. Although adhesion molecules have also been implicated in the pathogenesis of diabetes mellitus [32-33], there is little information 
about their relationship with metabolic control or their potential role in the pathogenesis of complications [11].

In the present study, the BMI and WC were shown to have small but significant positive correlations with hsCRP, sICAM-1, E-selectin $(\mathrm{p}<0.001)$ and IL-6 $(\mathrm{p}<0.01)$ and glucose showed positive correlations with hsCRP, sVCAM-1 and E-selectin. Actually, a number of prospective studies have shown that hs-CRP levels predict development of diabetes mellitus in different non-diabetic populations regardless the degree of adiposity, fat distribution and insulin resistance. All these studies were included in a review and meta-analysis which provided further evidence that elevated CRP levels are significantly associated with increased risk of T2DM (relative risk [RR] 1.26 [95\% confidence interval or CI 1.16-1.37]) [34]. This meta-analysis also detected a significant dose response association between IL-6 (its inducer) and T2DM risk (RR 1.31 [95\% CI 1.17-1.46]) [18,34]. However, since hs-CRP plasma levels have been associated with cardiovascular diseases and death in the general population [35] and in patients with metabolic syndrome [36], an important question is the possible association of inflammatory markers with these risks in T2DM patients. The Hoorn population-based study was the first to show that CRP is a predictor of mortality in T2DM individuals over a 5- to 7-year period [11,37].

In current study, the concentration of coronary risk biomarkers was similar across the metabolic syndrome subjects irrespective of their glycaemic status. This study further revealed that in this cohort of subjects, diastolic blood pressure is the independent predictor for high mean concentration of IL-6. However, the present study failed to demonstrate the association between fasting plasma glucose with any of the coronary risk biomarkers. The present data also raises a question on whether additional elevation of these biomarkers is associated with the severity of each metabolic syndrome parameter (e.g. established T2DM vs. newly diagnosed T2DM) or whether it is due to the number of metabolic syndrome parameters involved (e.g. having 4 metabolic syndrome parameters vs. 5 metabolic syndrome parameters). Therefore, it is recommended that future studies should include a longitudinal design in order to ascertain the influence of each metabolic syndrome parameter severity especially glycaemic status, from glucose intolerance to newly diagnose T2DM and established T2DM on the biomarkers concentration. 


\section{CONCLUSION}

MS subjects irrespective of glycaemic status have enhanced inflammation and endothelial activation compared to normal controls, which may partially explain their increased risk of developing coronary heart disease. This study further revealed that diastolic blood pressure is the independent predictor for high mean concentration of IL-6. However, the present study failed to demonstrate the association between fasting plasma glucose with any of the coronary risk biomarkers.

\section{ACKNOWLEDGEMENTS}

The authors would like to acknowledge the Ministry of Higher Education, Malaysia for financial support awarded to the corresponding author under the Long term Research Grant Scheme (LRGS), code: 600-RMI/LRGS 5/3 (2/2011) and UiTM for the clinical and laboratory facilities.

\section{REFERENCES}

[1] Kaur J. A comprehensive review on metabolic syndrome. Cardiology Research and Practice, 2014, 2014:1-21

[2] Alberti K G, Eckel R H, Grundy S M, Zimmet P Z, Cleeman J I, Donato K A, Fruchart J C, James W P, Loria C M, Smith S C. Harmonizing the metabolic syndrome. Circulation, 2009, 120(16):1640-1645

[3] Grundy S M, Cleeman J I, Daniels S R, Donato K A, Eckel R H, Franklin B A, Gordon D J, Krauss R M, Savage P J, Smith S C, Spertus J A. Diagnosis and management of the metabolic syndrome. Circulation, 2005, 112(17):2735-2752

[4] Wilson P W, D’Agostino R B, Parise H, Sullivan L, Meigs J B. Metabolic syndrome as a precursor of cardiovascular disease and type 2 diabetes mellitus. Circulation, 2005, 112(20):3066-3072

[5] Wender-Ozegowska E, Zawiejska A, Michalowska-Wender G, Iciek R, Wender M, Brazert J. Metabolic syndrome in type 1 diabetes mellitus. Does it have any impact on the course of pregnancy? Journal of Physiology and Pharmacology, 2011, 62(5):567-573

[6]McGill M, Molyneaux L, Twigg S M, Yue D K. The metabolic syndrome in type 1 diabetes: 
Does it exist and does it matter? Journal of Diabetes and Its Complications, 2008, 22(1):18-23 [7]Pambianco G, Costacou T, Orchard T J. The prediction of major outcomes of type 1 diabetes: A 12-year prospective evaluation of three separate definitions of the metabolic syndrome and their components and estimated glucose disposal rate. Diabetes Care, 2007, 30(5):1248-1254

[8]Thorn L, Forsblom C, Fagerudd J, Pettersson-Fernholm K, Saraheimo M, Waden J, Ronnback M, Rosengard-Barlund M, af Bjorkesten C G, Wessman M, Taskinen M R. Metabolic syndrome in type 1 diabetes: Association with diabetic nephropathy and glycaemic control (the FinnDiane study). Diabetes Care, 2005, 28(8):2019-2024

[9] Thorn L M, Forsblom C, Wadén J, Saraheimo M, Tolonen N, Hietala K, Groop P H, Finnish Diabetic Nephropathy (FinnDiane) Study Group. Metabolic syndrome as a risk factor for cardiovascular disease, mortality, and progression of diabetic nephropathy in type 1 diabetes. Diabetes Care, 2009, 32(5):950-952

[10] Perseghin G, Lattuada G, Danna M, Sereni L P, Maffi P, De Cobelli F, Battezzati A, Secchi A, Del Maschio A, Luzi L. Insulin resistance, intramyocellular lipid content, and plasma adiponectin in patients with type 1 diabetes. American Journal of Physiology-Endocrinology and Metabolism, 2003, 285(6):1174-1181

[11] Schaumberg D A, Glynn R J, Jenkins A J, Lyons T J, Rifai N, Manson J E, Ridker P M, Nathan D M. Effect of intensive glycemic control on levels of markers of inflammation in type 1 diabetes mellitus in the diabetes control and complications trial. Circulation, 2005, 111(19):2446-2453

[12] Laing S P, Swerdlow A J, Slater S D, Burden A C, Morris A, Waugh N R, Gatling W, Bingley P J, Patterson C C. Mortality from heart disease in a cohort of 23,000 patients with insulin-treated diabetes. Diabetologia, 2003, 46(6):760-765

[13] Green A, Hougaard P. Epidemiological studies of diabetes mellitus in Denmark: 5. Mortality and causes of death among insulin-treated diabetic patients. Diabetologia, 1984, 26(3):190-194

[14] Diabetes Control and Complications Trial, Epidemiology of Diabetes Interventions and Complications Research Group. Intensive diabetes therapy and carotid intima-media thickness in type 1 diabetes mellitus. New England Journal of Medicine, 2003, 348(23):2294-2303 
[15] Janowska J, Chudek J, Olszanecka-Glinianowicz M, Semik-Grabarczyk E, Zahorska-Markiewicz B. Interdependencies among selected pro-inflammatory markers of endothelial dysfunction, c-peptide, anti-inflammatory interleukin-10 and glucose metabolism disturbance in obese women. International Journal of Medical Sciences, 2016, 13(7):490-499

[16] Ding H, Triggle CR. Endothelial cell dysfunction and the vascular complications associated with type 2 diabetes: Assessing the health of the endothelium. Vascular Health and Risk Management, 2005, 1(1):55-71

[17] Bakker W, Eringa E C, Sipkema P, van Hinsbergh V W. Endothelial dysfunction and diabetes: Roles of hyperglycemia, impaired insulin signaling and obesity. Cell and Tissue Research, 2009, 335(1):165-189

[18] Esser N, Legrand-Poels S, Piette J, Scheen A J, Paquot N. Inflammation as a link between obesity, metabolic syndrome and type 2 diabetes. Diabetes Research and Clinical Practice, 2014, 105(2):141-150

[19] Chedraui P, Pérez-López F R, Escobar G S, Palla G, Montt-Guevara M, Cecchi E, Genazzani A R, Simoncini T, Research Group for the Omega Women's Health Project. Circulating leptin, resistin, adiponectin, visfatin, adipsin and ghrelin levels and insulin resistance in postmenopausal women with and without the metabolic syndrome. Maturitas, 2014, 79(1):86-90

[20] Filippatos T D, Derdemezis C S, Gazi I F, Lagos K, Kiortsis D N, Tselepis A D, Elisaf M S. Increased plasma visfatin levels in subjects with the metabolic syndrome. European Journal of Clinical Investigation, 2008, 38(1):71-72

[21] Indulekha K, Surendar J, Mohan V. High sensitivity C-reactive protein, tumor necrosis factor- $\alpha$, interleukin-6, and vascular cell adhesion molecule-1 levels in Asian Indians with metabolic syndrome and insulin resistance (CURES-105). Journal of Diabetes Science and Technology, 2011, 5(4):982-988

[22] Dallmeier D, Larson M G, Vasan R S, Keaney J F, Fontes J D, Meigs J B, Fox C S, Benjamin E J. Metabolic syndrome and inflammatory biomarkers: A community-based cross-sectional study at the Framingham Heart Study. Diabetology and Metabolic Syndrome, $2012,4(1): 28$

[23] Chen SJ, Yen CH, Huang YC, Lee BJ, Hsia S, Lin PT. Relationships between 
inflammation, adiponectin, and oxidative stress in metabolic syndrome. Plos One, 2012, $7(9): 1-5$

[24] Palomo I G, Jaramillo J C, Alarcón M L, Gutiérrez C L, Moore-Carrasco R, Segovia F M, Leiva E M, Mujica V E, Icaza G, Dí N S. Increased concentrations of soluble vascular cell adhesion molecule-1 and soluble CD40L in subjects with metabolic syndrome. Molecular Medicine Reports, 2009, 2(3):481-485

[25] Nishida M, Moriyama T, Sugita Y, Yamauchi-Takihara K. Abdominal obesity exhibits distinct effect on inflammatory and anti-inflammatory proteins in apparently healthy Japanese men. Cardiovascular Diabetology, 2007, 6(1):1-5

[26] Faam B, Zarkesh M, Daneshpour M S, Azizi F, Hedayati M. Association between abdominal obesity and HS-CRP, IL-6 and HCY in Tehranian adults: TLGS. Iranian Journal of Diabetes and Metabolism, 2014, 13(2):163-171

[27] Lapice E, Maione S, Patti L, Cipriano P, Rivellese A A, Riccardi G, Vaccaro O. Abdominal adiposity is associated with elevated C-reactive protein independent of BMI in healthy nonobese people. Diabetes Care, 2009, 32(9):1734-1736

[28] American Diabetes Association. Diagnosis and classification of diabetes mellitus. Diabetes Care, 2014, 37(Supplement 1):S81-90

[29] Ahirwar A K, Jain A, Goswami B, Bhatnagar M K, Bhatacharjee J. Imbalance between protective (adiponectin) and prothrombotic (Plasminogen Activator Inhibitor-1) adipokines in metabolic syndrome. Diabetes and Metabolic Syndrome: Clinical Research and Reviews, $2014,8(3): 152-155$

[30] Gearing A J, Newman W. Circulating adhesion molecules in disease. Immunology Today, 1993, 14(10):506-512

[31] Roep B O, de Vries R R, Heidenthal E, Kolb H, Martin S. Soluble forms of intercellular adhesion molecule-1 in insulin-dependent diabetes mellitus. The Lancet. 1994, 343(8913):1590-1593

[32] Lampeter E R, Kishimoto T K, Rothlein R, Mainolfi E A, Bertrams J, Kolb H, Martin S. Elevated levels of circulating adhesion molecules in IDDM patients and in subjects at risk for IDDM. Diabetes, 1992, 41(12):1668-1671

[33] Yang X D, Michie S A, Roland T, Weissman I, McDevitt H O. The role of cell adhesion 
molecules in the development of IDDM: Implications for pathogenesis and therapy. Diabetes, $1996,45(6): 705-710$

[34] Wang X, Bao W, Liu J, OuYang Y Y, Wang D, Rong S, Xiao X, Shan Z L, Zhang Y, Yao P, Liu L G. Inflammatory markers and risk of type 2 diabetes. Diabetes Care, 2013, 36(1):166-175

[35] Blake G J, Ridker P M. Inflammatory bio-markers and cardiovascular risk prediction. Journal of Internal Medicine, 2002, 252(4):283-294

[36] Ridker P M, Buring J E, Cook N R, Rifai N. C-reactive protein, the metabolic syndrome, and risk of incident cardiovascular events. Circulation. 2003, 107(3):391-397

[37] Jager A, van Hinsbergh V W, Kostense P J, Emeis J J, Yudkin J S, Nijpels G, Dekker J M, Heine R J, Bouter L M, Stehouwer C D. von Willebrand factor, C-reactive protein, and 5-year mortality in diabetic and nondiabetic subjects. Arteriosclerosis, Thrombosis, and Vascular Biology, 1999, 19(12):3071-3078

[38] Alberti K G, Zimmet P, Shaw J. Metabolic syndrome-A new world-wide definition: A consensus statement from the International Diabetes Federation. Diabetic Medicine, 2006, 23(5):469-480

\section{How to cite this article:}

Osman M.T, Mohd Nasir N, Ramli A.S, Saimin H, Rahman T, Abdul Razak S, Ismail Z, and Nawawi M H. Enhanced inflammation in subgroups of metabolic syndrome irrespective to glycaemic status. J. Fundam. Appl. Sci., 2017, 9(6S), 331-349. 